\title{
No Association between PAWR Gene Polymorphisms and Tardive Dyskinesia in Schizophrenia Patients
}

\author{
II-Soo Kim ${ }^{1,2}$, Ho-Kyoung Yoon ${ }^{1}$, Seung-Gul Kang ${ }^{3}$, Young-Min Park ${ }^{4}$, Yong-Ku Kim¹, \\ Seung-Hyun Kim ${ }^{1}$, Jung-Eun Choi ${ }^{1,5}$, Leen $\mathrm{Kim}^{1}$ and Heon-Jeong Lee ${ }^{1,5} \bowtie$ \\ ${ }^{1}$ Departments of Psychiatry and ${ }^{2}$ Medicine, Korea University School of Medicine, Seoul, Korea \\ ${ }^{3}$ Department of Psychiatry, Gachon University of Medicine and Science, Incheon, Korea \\ ${ }^{4}$ Department of Psychiatry, Inje University College of Medicine, Goyang, Korea \\ ${ }^{5}$ Division of Brain Korea 21 Biomedical Science, Korea University College of Medicine, Seoul, Korea
}

Tardive dyskinesia (TD) is a hyperkinetic movement disorder associated with the prolonged use of antipsychotic drugs. Since prostate apoptosis response 4 (Par-4) is a key ligand of the dopamine D2 receptor, the Par-4 gene (PAWR) is a good candidate gene to study in the context of TD susceptibility. We examined the association between PAWR gene polymorphisms and TD. Three single nucleotide polymorphisms of PAWR were selected for the analysis: rs7979987, rs4842318, and rs17005769. Two hundred and eighty unrelated Korean schizophrenic patients participated in this study (105 TD and 175 non-TD patients). Genotype/allele-wise and haplotype-wise analyses were performed. There were no significant differences in genotype and allele frequencies between the two groups. Haplotype analysis also did not reveal a difference between the two groups. Within the limitations imposed by the size of the clinical sample, these findings suggest that PAWR gene variants do not significantly contribute to an increased risk of TD.

Psychiatry Investig 2012;9:191-194

Key Words Schizophrenia, Tardive dyskinesia, PAWR, Polymorphism.

\section{INTRODUCTION}

Tardive dyskinesia (TD) is a hyperkinetic movement disorder associated with the prolonged use of antipsychotic drugs. ${ }^{1}$ The annual incidence was reported to be $3.9 \%$ for secondgeneration antipsychotics and $5.5 \%$ for first-generation antipsychotics, while the prevalence is $13.1 \%$ for second-generation antipsychotics, $15.6 \%$ for antipsychotic-free patients, and $32.4 \%$ for first-generation antipsychotics. ${ }^{2}$ Although hypotheses such as dopamine receptor supersensitivity, imbalance between D1 and D2 receptor-mediated effects and the GABA hypothesis have been suggested, the pathophysiology of TD is not well defined. ${ }^{1,3-9}$ Among the risk factors known for TD, age is the most robust. ${ }^{10-13}$ Other risk factors include nonwhite ethnicity, extrapyramidal symptoms, lack of response to

Received: March 25, 2012 Revised: April 27, 2012

Accepted: April 27, 2012 Available online: May 22, 2012

$\triangle$ Correspondence: Heon-Jeong Lee, $\mathrm{MD}, \mathrm{PhD}$

Department of Psychiatry, Anam Hospital, Korea University College of Medicine, 73 Inchon-ro, Seongbuk-gu, Seoul 136-705, Korea

Tel: +82-2-920-6721, Fax: +82-2-929-7679, E-mail: leehjeong@korea.ac.kr

(a) This is an Open Access article distributed under the terms of the Creative Commons Attribution Non-Commercial License (http://creativecommons.org/licenses/bync/3.0) which permits unrestricted non-commercial use, distribution, and reproduction in any medium, provided the original work is properly cited. treatment, worse premorbid functioning, negative symptoms, long treatment duration, worsening of psychosis and prolactine-related sexual dysfunction. ${ }^{14}$

Genetic susceptibility has been also examined in many studies. There have been substantial case-control association studies on TD, and a number of studies have been conducted on the genes involved in drug metabolism such as cytochrome P450 (CYP), monoamine receptor genes, and oxidative stress related genes. As a result, relatively consistent findings have been reported for certain polymorphisms such as CYP2D $6 * 10,{ }^{15}$ dopamine D2 receptor (DRD2) Taq1A, ${ }^{16}$ dopamine D3 receptor (DRD3) Ser9Gly, ${ }^{17}$ serotonin 2A receptor (HTR2A) T102C, ${ }^{18}$ and manganese superoxide dismutase (MnSOD) Ala9Val, ${ }^{19,20}$ though they are still controversial.

Recently, Park et al. ${ }^{21}$ identified prostate apoptosis response 4 (Par-4) as a regulatory component in dopamine signaling. In their model of the involvement of Par- 4 in the regulation of DRD2 signaling, Par-4/DRD2 complex formation via the calmodulin binding motif in the third cytoplasmic loop was suggested to inhibit cAMP signaling from DRD2. Moreover, they also observed that a mutant mouse lacking the DRD2 interaction domain of Par-4 displayed depression-like behaviors. 
Since TD mainly develops in patients treated with a DRD2 blocker, the Par-4 gene (PAWR) could be associated with TD. In this study, we selected three SNPs of PAWR and examined their association with TD susceptibility in Korean schizophrenia patients.

\section{METHODS}

\section{Subjects and assessment}

All subjects were ethnically homogeneous Korean and were examined by trained psychiatrists using the Korean version of the Structured Clinical Interview for DSM-IV, leading to a diagnosis based on DSM-IV criteria. ${ }^{22}$ Written informed consent was obtained from each patient, and the study protocol was approved by the Ethics Committee of the Korea University Medical Center. None of the patients had a significant comorbid neurological illness, mental retardation, or history of substance abuse. All subjects were inpatients at collaborating hospitals of Korea University. Other findings from these subjects have been reported previously. ${ }^{20,23-28}$

Assessment with the Abnormal Involuntary Movement Scale (AIMS) ${ }^{29}$ was used to recruit 105 schizophrenic patients with TD and 175 schizophrenic patients without TD. Our test sample included TD patients who had received atypical antipsychotic treatment (25 patients), which reportedly has a lower risk of TD than typical antipsychotic treatment, and who had been treated for less than ten years (18 patients). All of the non-TD patients in the test sample had received typical antipsychotic treatment for at least ten years. We applied these different inclusion criteria since the occurrence of TD in patients treated for less than ten years is indicative of a higher genetic susceptibility. Their current antipsychotic dosages were converted into chlorpromazine equivalents. All patients were maintained on stable dosages of antipsychotics for at least three\&\#160;months before the assessment of TD. The TD diagnosis was performed according to the Research Diagnostic Criteria for TD (RDC-TD) on the basis of AIMS. ${ }^{30} \mathrm{We}$ rated the first seven items of the AIMS to determine the total AIMS score of abnormal movements in the patients. Subjects with two or more two-point ratings or one or more threepoint ratings on the first seven items of the AIMS were diagnosed with TD according to RDC-TD. Clinical symptoms were measured by the Positive and Negative Syndrome Scale (PANSS). ${ }^{31}$

\section{Genetic markers}

Three single nucleotide polymorphisms (SNPs) were selected for the analysis: rs7979987, rs4842318, and rs17005769. To evaluate the coverage rate of the three SNPs for the total PAWR gene variation we consulted the HapMap database (release \#27, population: CHB, http://hapmap.ncbi.nlm.nih. gov). There were 41 SNPs reported to have a minimal allele frequency of more than 0.1 . We performed 2- and 3- marker aggressive tagging using the Tagger program implemented in Haploview 4.2 (http://www.broadinstitute.org/haploview). We found that 35 of 41 (85\%) SNPs were captured by the three SNPs.

\section{Genotyping}

Blood samples $(5-10 \mathrm{~mL})$ from subjects were collected in EDTA, and genomic DNA was isolated using a NucleoSpin ${ }^{\circledR}$ Blood DNA Extraction Kit (Macherey-Nagel, Germany) according to the manual. Genotyping was performed by highresolution melting (HRM) curve analysis. PCR was performed in a volume of $20 \mu \mathrm{L}$ per reaction with a 96-well BioRad CFX96 Real Time PCR System (Bio-Rad, Hercules, CA, USA). Reaction mixtures included $1.5 \mu \mathrm{L}$ of genomic DNA as template, $200 \mathrm{mM}$ of each primer [rs7979987-F: GGA CAT TAT CTC TGG GTT AG, rs7979987-R: ACA TAA GCA CAT ACA CCA AC, rs4842318-F: GAA GGC TAC ACG CTA CAT T, rs4842318-R: AGA TGA GTC TGA AGG TCC AAT A, rs17005769-F: TCT ACA ATC TGT CCT TAG AAA CTT AA, rs17005769-R: CTT TCA AGG TTG TTA ATG GCA TAA] (BMS, Daejeon, Korea), 1×Sso Fast EvaGreen SuperMix (Bio-Rad), and sterile $\mathrm{H} 2 \mathrm{O}$. The amplification protocol started with $98^{\circ} \mathrm{C} / 3$ min followed by 39 cycles of $98^{\circ} \mathrm{C} / 10 \mathrm{~s}$ and $58^{\circ} \mathrm{C} / 20 \mathrm{~s}$. After an initial step of $95^{\circ} \mathrm{C} / 10 \mathrm{~s}$ and $65^{\circ} \mathrm{C} / 10 \mathrm{~s}$, melting curves were generated from $65^{\circ} \mathrm{C}$ to $95^{\circ} \mathrm{C}$ in increments of $0.3^{\circ} \mathrm{C} /$ cycle. Melting profiles were analyzed with the Bio-Rad Precision Melt Software.

\section{Statistical analysis}

Differences between categorical and continuous variables were evaluated by the chi-square test and Student's t-test, respectively. The total PANSS and AIMS scores were evaluated by ANCOVA with sex, age, duration of antipsychotics and smoking status as covariates. Genotype deviation from Hardy-Weinberg equilibrium (HWE) was evaluated by the chisquare test for goodness of fit. Haplotype analysis was performed using the UNPHASED 3.1.4 software. ${ }^{32}$ A power calculation was performed using $G^{*}$ Power3.1.3. ${ }^{33}$ The cutoff p-value was set at 0.05 .

\section{RESULTS}

There were significant differences in age (non-TD: 43.47 \pm 9.174 years; TD: $46.29 \pm 9.722$ years, $\mathrm{p}=0.016)$ and smoking status of female subjects (non-TD: smoker/nonsmoker= 18/64, TD: smoker/nonsmoker $=21 / 27, \mathrm{p}=0.009$ ), while no significant differences were observed between groups with re- 
gard to sex, duration of illness, duration of antipsychotic treatment, current antipsychotic dosage and smoking status. Total AIMS scores (mean \pm SD) were higher in TD subjects (non-TD: $0.74 \pm 1.062$ vs. TD: $7.66 \pm 4.287, \mathrm{p}=0.010$ ). Total PANSS scores were not significantly different (non-TD: 87.87 \pm 18.77 vs. TD: $92.43 \pm 19.49, \mathrm{p}=0.095)$ although the general PANSS subscores were higher in TD patients than in non-TD patients (non-TD: $42.87 \pm 9.80$ vs. TD: $46.29 \pm 11.07, \mathrm{p}=0.010$ ). Genotype frequencies of all SNPs were in Hardy-Weinberg equilibrium. There were no significant differences in genotype or allele frequencies between the two groups (Table 1). Haplotype analysis also detected no significant difference between the two groups in either two- (data not shown) or threemarker haplotypes (Table 2).

\section{DISCUSSION}

Prostate apoptosis response-4 (Par-4) is a key ligand of DRD2. Par-4 is expressed in the striatal neurons along with DRD2 and interacts with DRD2 in neural cells. ${ }^{34}$ Par-4 normally enhances DRD2 signaling and thereby inhibits dopamine/DRD2-mediated neurotransmission. ${ }^{21}$ Par-4 specifically interacts with DRD2 via its leucine domain, and it can be coimmunoprecipitated with DRD2 in mouse brain lysate. Once DRD2 is activated, Par-4/DRD2 complex formation is necessary for the maintenance of inhibitory tone in dopamine-mediated CAMP signaling. The binding of Par-4 to DRD2 regu- lates cAMP signaling, and subsequently affects the function of the DA-cAMP-CREB pathway. ${ }^{21}$ Therefore, Par-4 (PAWR) is a good candidate gene to study in the context of TD.

However, in this study, the three PAWR SNPs we analyzed were not associated with TD in terms of genotype, allele, or haplotype. These findings indicate that PAWR may not related to TD susceptibility. However, it is still possible that other regions of the PAWR gene are associated with TD. The studied SNPs only captured approximately $85 \%$ of the genetic variations in the PAWR gene according to the HapMap database. On the other hand, it is also possible that the regulatory regions outside of the PAWR gene are associated with TD. The negative association of the analyzed SNPs could be due to type II error. The power was 0.86 and 0.92 to detect an effect size of 0.20 in the analysis of genotype and allele frequencies, respectively. There are additional limitations to generalization of the results of this study. Although anticholinergics and benzodiazepines had been reported to be beneficial in some cases of TD, we could not control these drugs. There was significant age difference between the TD and non-TD group, although we tried to control the age as a covariate in some analyses. Recently, Liou et al. ${ }^{35}$ tested whether variation in the PAWR gene might be related to TD susceptibility with five SNPs as genetic markers: rs1705769, rs7305141, rs8176874, rs7955388 and rs2307220. However, their results did not indicate any association between PAWR genetic polymorphisms and TD. Our finding supports their results. In conclusion, we

Table 1. PAWR Genotype and allele distributions between TD and non-TD subjects

\begin{tabular}{|c|c|c|c|c|c|c|c|c|c|c|c|}
\hline \multirow{2}{*}{ SNP ID } & \multirow{2}{*}{ Position } & \multirow{2}{*}{$\begin{array}{c}\text { Allele } \\
1 / 2\end{array}$} & \multirow{2}{*}{ Phenotype } & \multicolumn{3}{|c|}{ Genotype } & \multicolumn{2}{|c|}{ Allele } & \multicolumn{3}{|c|}{$\mathrm{p}$ value } \\
\hline & & & & $1 / 1$ & $1 / 2$ & $2 / 2$ & 1 & 2 & Genotype & Allele & HWE \\
\hline \multirow[t]{2}{*}{ rs7979987 } & 78522768 & $\mathrm{G} / \mathrm{C}$ & Non-TD & 103 & 64 & 8 & 0.7714 & 0.2286 & 0.469 & 0.354 & 0.953 \\
\hline & & & TD & 66 & 37 & 2 & 0.8048 & 0.1952 & & & 0.630 \\
\hline \multirow[t]{2}{*}{ rs4842318 } & 78568298 & $\mathrm{C} / \mathrm{T}$ & Non-TD & 70 & 92 & 13 & 0.6629 & 0.3371 & 0.660 & 0.713 & 0.226 \\
\hline & & & TD & 42 & 52 & 11 & 0.6476 & 0.3524 & & & 0.830 \\
\hline \multirow[t]{2}{*}{ rs17005769 } & 78579258 & $\mathrm{~T} / \mathrm{C}$ & Non-TD & 94 & 75 & 6 & 0.7514 & 0.2486 & 0.651 & 0.726 & 0.314 \\
\hline & & & TD & 56 & 43 & 6 & 0.7381 & 0.2619 & & & 0.935 \\
\hline
\end{tabular}

TD: tardive dskinesia, HWE: Hardy-Weinberg Equilibrium, SNP: single nuclotide polymorphism

Table 2. Haplotype analysis for PAWR between TD and non-TD subjects

\begin{tabular}{|c|c|c|c|c|}
\hline \multirow{2}{*}{$\begin{array}{c}\text { Haplotype } \\
\text { (rs7979987, rs4842318, rs17005769) }\end{array}$} & \multirow{2}{*}{ Overall $p$ value } & \multicolumn{2}{|c|}{ Haplotype frequencies } & \multirow{2}{*}{$\mathrm{p}$ value } \\
\hline & & Non-TD & TD & \\
\hline C-C-T & \multirow{6}{*}{0.80} & 0.229 & 0.189 & 0.300 \\
\hline C-T-T & & 0.000 & 0.006 & 0.378 \\
\hline G-C-C & & 0.241 & 0.256 & 0.718 \\
\hline G-C-T & & 0.194 & 0.203 & 0.815 \\
\hline G-T-C & & 0.008 & 0.006 & 0.968 \\
\hline G-T-T & & 0.329 & 0.340 & 0.771 \\
\hline
\end{tabular}

TD: tardive dyskinesia 
did not identify any association between three PAWR SNPs and TD in Korean schizophrenia patients. However, further studies with a larger sample size and more genetic markers will be necessary to confirm these results.

\section{Acknowledgments}

This study was supported by the Korean Society of Schizophrenia Research and a grant from the Korea Research Foundation funded by the Korean government (KRF-2010-0025130).

\section{REFERENCES}

1. Tarsy D, Baldessarini RJ. Tardive dyskinesia. Annu Rev Med 1984;35: 605-623.

2. Correll CU, Schenk EM. Tardive dyskinesia and new antipsychotics. Curr Opin Psychiatry 2008;21:151-156.

3. Tarsy D, Baldessarini RJ. Behavioural supersensitivity to apomorphine following chronic treatment with drugs which interfere with the synaptic function of catecholamines. Neuropharmacology 1974;13:927-940.

4. Lee T, Seeman P, Tourtellotte WW, Farley IJ, Hornykeiwicz O. Binding of $3 \mathrm{H}$-neuroleptics and $3 \mathrm{H}$-apomorphine in schizophrenic brains. Nature 1978;274:897-900.

5. Gerlach J, Hansen L. Clozapine and D1/D2 antagonism in extrapyramidal functions. Br J Psychiatry Suppl 1992;17:34-37.

6. Trugman JM. Tardive dyskinesia: Diagnosis, pathogenesis, and management. Neurologist 1998;4:180-187.

7. Gunne LM, Haggstrom JE, Sjoquist B. Association with persistent neuroleptic-induced dyskinesia of regional changes in brain GABA synthesis. Nature 1984;309:347-349.

8. De Keyser J. Excitotoxic mechanisms may be involved in the pathophysiology of tardive dyskinesia. Clin Neuropharmacol 1991;14:562565.

9. Lee HJ, Kang SG. Genetics of tardive dyskinesia. Int Rev Neurobiol 2011;98:231-264.

10. Smith JM, Baldessarini RJ. Changes in prevalence, severity, and recovery in tardive dyskinesia with age. Arch Gen Psychiatry 1980;37:13681373.

11. Kane JM, Woerner M, Weinhold P, Wegner J, Kinon B. A prospective study of tardive dyskinesia development: preliminary results. J Clin Psychopharmacol 1982;2:345-349.

12. Correll CU, Leucht S, Kane JM. Lower risk for tardive dyskinesia associated with second-generation antipsychotics: a systematic review of 1-year studies. Am J Psychiatry 2004;161:414-425.

13. Jeste DV. Tardive dyskinesia in older patients. J Clin Psychiatry 2000; 61(Suppl 4):27-32.

14. Tenback DE, van Harten PN. Epidemiology and risk factors for (tardive) dyskinesia. Int Rev Neurobiol 2011;98:211-230.

15. Lam LC, Garcia-Barcelo MM, Ungvari GS, Tang WK, Lam VK, Kwong SL, et al. Cytochrome P450 2D6 genotyping and association with tardive dyskinesia in Chinese schizophrenic patients. Pharmacopsychiatry 2001;34:238-241.

16. Chen CH, Wei FC, Koong FJ, Hsiao KJ. Association of TaqI A polymorphism of dopamine D2 receptor gene and tardive dyskinesia in schizophrenia. Biol Psychiatry 1997;41:827-829.

17. Tsai HT, North KE, West SL, Poole C. The DRD3 rs6280 polymorphism and prevalence of tardive dyskinesia: a meta-analysis. Am J Med Genet B Neuropsychiatr Genet 2010;153B:57-66.

18. Segman RH, Heresco-Levy U, Finkel B, Inbar R, Neeman T, Schlafman $\mathrm{M}$, et al. Association between the serotonin $2 \mathrm{C}$ receptor gene and tar- dive dyskinesia in chronic schizophrenia: additive contribution of 5-HT2Cser and DRD3gly alleles to susceptibility. Psychopharmacology (Berl) 2000;152:408-413.

19. Akyol O, Yanik M, Elyas H, Namli M, Canatan H, Akin H, et al. Association between Ala-9Val polymorphism of Mn-SOD gene and schizophrenia. Prog Neuropsychopharmacol Biol Psychiatry 2005;29:123131.

20. Kang SG, Choi JE, An H, Park YM, Lee HJ, Han C, et al. Manganese superoxide dismutase gene Ala-9Val polymorphism might be related to the severity of abnormal involuntary movements in Korean schizophrenic patients. Prog Neuropsychopharmacol Biol Psychiatry 2008;32: 1844-1847.

21. Park SK, Nguyen MD, Fischer A, Luke MP, Affar el B, Dieffenbach PB, et al. Par-4 links dopamine signaling and depression. Cell 2005;122: 275-287.

22. Han OS, Hong JP. Structured Clinical Interview for DSM-IV Axis I Disorder-Korean Version. Seoul: Hana Medical Publishing; 2000.

23. Lee HJ, Kang SG, Choi JE, Paik JW, Kim YK, Kim SH, et al. No association between dopamine $\mathrm{D} 4$ receptor gene $-521 \mathrm{C} / \mathrm{T}$ polymorphism and tardive dyskinesia in schizophrenia. Neuropsychobiology. 2007;55:4751.

24. Lee HJ, Kang SG, Paik JW, Lee MS, Cho BH, Park YM, et al. No evidence for an association between $\mathrm{G}$ protein beta3 subunit gene C825T polymorphism and tardive dyskinesia in schizophrenia. Hum Psychopharmacol 2007;22:501-504.

25. Kang SG, Choi JE, An H, Lim SW, Lee HJ, Han C, et al. No association between the brain-derived neurotrophic factor gene Val66Met polymorphism and tardive dyskinesia in schizophrenic patients. Prog Neuropsychopharmacol Biol Psychiatry 2008;32:1545-1548.

26. Kang SG, Choi JE, Park YM, Lee HJ, Han C, Kim YK, et al. Val158Met polymorphism in the catechol-O-methyltransferase (COMT) gene is not associated with tardive dyskinesia in schizophrenia. Neuropsychobiology 2008;57:22-25.

27. Kang SG, Lee HJ, Choi JE, An H, Rhee M, Kim L. Association study between glutathione S-transferase GST-M1, GST-T1, and GST-P1 polymorphisms and tardive dyskinesia. Hum Psychopharmacol 2009; 24:55-60.

28. Park YM, Kang SG, Choi JE, Kim YK, Kim SH, Park JY, et al. No Evidence for an Association between Dopamine D2 Receptor Polymorphisms and Tardive Dyskinesia in Korean Schizophrenia Patients. Psychiatry Investig 2011;8:49-54.

29. Guy W. ECDEU Assessment Manual for Psychopharmacology. Washington, DC: Dept of Health, Education and Welfare, 1976, p. 534-537.

30. Schooler NR, Kane JM. Research diagnoses for tardive dyskinesia. Arch Gen Psychiatry 1982;39:486-487.

31. Kay SR, Fiszbein A, Opler LA. The positive and negative syndrome scale (PANSS) for schizophrenia. Schizophr Bull 1987;13:261-276.

32. Dudbridge F. Likelihood-based association analysis for nuclear families and unrelated subjects with missing genotype data. Hum Hered 2008; 66:87-98.

33. Faul F, Erdfelder E, Buchner A, Lang AG. Statistical power analyses using $G^{\star}$ Power 3.1: Tests for correlation and regression analyses. Behav Res Methods 2009;41:1149-1160.

34. Mattson MP, Gleichmann M. The neuronal death protein par-4 mediates dopaminergic synaptic plasticity. Mol Interv 2005;5:278-281.

35. Liou YJ, Chen ML, Wang YC, Chen JY, Liao DL, Bai YM, et al. Analysis of genetic variations in the human Par-4 (PAWR) gene and tardive dyskinesia in schizophrenia. Am J Med Genet B Neuropsychiatr Genet 2009;150B:439-440. 